\title{
KNOWLEDGE EXCHANGE IN ELECTRONIC NETWORKS OF PRACTICE: Toward a Conceptual Framework
}

\author{
Eoin Whelan \\ National University of Ireland \\ Galway, Ireland
}

\begin{abstract}
The recently developed knowledge-based view of the firm argues that knowledge is the firm's most valuable resource. Within this field of study, informal social networks are rapidly gaining attention as mechanisms that facilitate knowledge flows. Electronic networks of practice are a special case of informal networks where the sharing of practice-related knowledge occurs primarily through computer-based communication technologies. However, we know relatively little about the dynamics of knowledge exchange that occur in these electronic networks. This paper posits that there is a relationship between the structural properties of electronic networks of practice and successful knowledge exchange. The theoretical positions of social network theory and the knowledge-based view of the firm are used to support this claim.
\end{abstract}

Keywords Knowledge, networks of practice, electronic community, social networks

\section{INTRODUCTION}

Over the past two decades, as a result of managerial initiatives such as delayering, reengineering and team-based designs, most organizations have become flatter and more flexible. This has significantly changed the way work gets done. Employees are no longer constrained by the role of formally prescribed relationships in organizations. More work is being done through informal networks and "supporting collaboration and work in these informal networks is increasingly important for organizations competing on knowledge and an ability to innovate and adapt" (Cross et al. 2002). Informal relationships among employees are often far more reflective of the way work happens

Please use the following format when citing this chapter:

Whelan, Eoin, 2006, in International Federation for Information Processing (IFIP), Volume 206, The Transfer and Diffusion of Information Technology for Organizational Resilience, eds. B. Donnellan, Larsen T., Levine L., DeGross J. (Boston: Springer), pp. 21-31. 
in an organization than the relationships established by position within the formal structure (Cross et al. 2002). Yet, these relationships rarely appear on formal organizational charts.

Further pressure is being placed on organizations by the increased internationalization of business resulting in collaboration and cooperation becoming more distributed. Collaboration between organizations has come into focus in recent years with the recognition that success in a global economy comes from innovation. This is the only way an organization can keep pace with the rapid developments in technology, increasingly demanding customers, and changes in the competitive environment through deregulation, social changes, and the actions of competitors. Innovation depends on the exchange of ideas and insights through trusted relationships, which depend on knowing how to collaborate effectively (Nooteboom 2004).

The diffusion of innovative knowledge has become one of the major research interests in management. Traditional organizational forms (markets and hierarchies) show serious deficits in organizing the complex nature of knowledge (Jones et al. 1997). This has led to an increased interest in the community of practice $(\mathrm{CoP})$ concept. A CoP consists of a relatively tight-knit group of members who know each other, work together face-to-face, and continually negotiate, communicate, and coordinate with each other directly. CoPs are regarded as the essential building blocks of the knowledge economy and are being promoted within organizations as sources of competitive advantage (Teigland and Wasko 2004). Current research has focused on the role of CoPs for encouraging knowledge exchange and innovation within organizations; however, we know much less about the role that members of CoP play in creating linkages to external knowledge sources. Previous research has found that organizational members may simultaneously be members of a $\mathrm{CoP}$ as well as members of broader occupational communities (Van Maanen and Barley 1984). These individuals perform the dual roles of generating local knowledge within an organizational $\mathrm{CoP}$ while providing linkages to knowledge and innovations outside of the organization. These inter-organizational networks have been referred to as networks of practice (NoPs). NoPs are social structures linking similar individuals across organizations who are engaged in a shared practice but who do not necessarily know one another (Brown and Duguid 2000).

While the participation of individuals in NoPs is not a new phenomenon, the ability to access these networks has increased due to recent advances in information and communication technologies. Electronic networks of practice (ENoPs) are a special case of NoP where the sharing of practice-related knowledge occurs primarily through computer-based communication technologies (Wasko and Faraj 2005). In ENoPs, individuals may never get to know one another or meet face-to-face. They generally coordinate through technologies such as blogs, listservs, or bulletin boards. Previous research has shown that external knowledge trading through ENoPs is beneficial for the firm (Bouty 2000; Teigland and Wasko 2003), thus making the study of ENoPs of prime interest for researchers and practitioners.

This paper examines ENoPs through the theoretical lens of social network theory. This body of literature shows that particular structural properties of networks create or constrain possibilities for action by individuals and networks. The overarching goal of this research-in-progress is to improve our understanding of electronic networks from a business firm's perspective, and in particular to investigate issues of structure and 
performance, two important areas generally left by the wayside in previous NoP research. This paper posits that there is a relationship between the structural properties of ENoPs and successful knowledge exchange. To support this claim, a review of the knowledge-based view of the firm is presented in section 2. A conceptual framework, which links the roles of CoPs to ENoPs within the knowledge-based view of the firm, is presented in section 3 . Section 4 gives a brief overview social network theory. Given the size constraints of this paper, we have chosen to focus on one particular structural property, core/periphery structure. The relationship between the core/periphery structure of a network and performance is explored further in this section. Finally, the mechanisms to be used to examine ENoP structure and knowledge exchange are detailed in section 5 .

\section{KNOWLEDGE-BASED VIEW OF THE FIRM}

This study is grounded in the knowledge-based view of the firm. This recently developed theory argues that knowledge is the firm's most valuable resource. Producing unique products and services or producing them at a lower cost than competitors is based on superior knowledge of the production process and superior design. In fact, prominent authors such as Drucker (1994), Grant (1996, 2001), and Spender (2003) suggest that knowledge is perhaps the only true source of competitive advantage.

Much tension exists as to the different views of knowledge. This debate is essentially centered on whether knowledge can be captured, stored, and transferred. Many people feel that if something is to be managed, it must be able to be quantified, counted, organized, and measured (Glazer 1998), and it must be able to be built, owned, controlled and its value maximized (Davenport 1997). This view of management has influenced attempts to manage knowledge by quantifying, capturing and controlling it as an object. The emerging field of knowledge management (KM) has also attracted some criticism because of this view, much of which relates to the perceived overemphasis on codifying and storing knowledge as data. There is a real danger that KM is just becoming another label for information systems rather than an innovative attempt to increase knowledge in the organization (Goldkuhl and Barf 2002). More recent developments have recognized that this approach to $\mathrm{KM}$ is too restrictive and that some aspects of knowledge cannot be captured. This debate has led to a confused picture of knowledge within the KM community as researchers and practitioners have sought to define the knowledge that can be captured and that which cannot. For example, some commentators are of the opinion that tacit knowledge can be captured (Huang 1997), some feel it is merely difficult to articulate (Teece 1998), others feel it cannot be codified without being invalidated (Buckingham Shum 1997), whereas still others feel it simply cannot be captured or codified at all (Leonard and Sensiper 1998).

There is a clear need for a different view of knowledge in order to overcome this challenge of managing knowledge that cannot be captured, codified, and stored. In this regard, Hildreth and Kimble (2002) argue that knowledge is not made up of mutually exclusive opposites of hard and soft (see Figure 1). Instead, they are mutually dependent where all knowledge is regarded as being both hard and soft. Only the proportions differ. Viewing knowledge in this way lends itself more easily to the notion that knowl- 


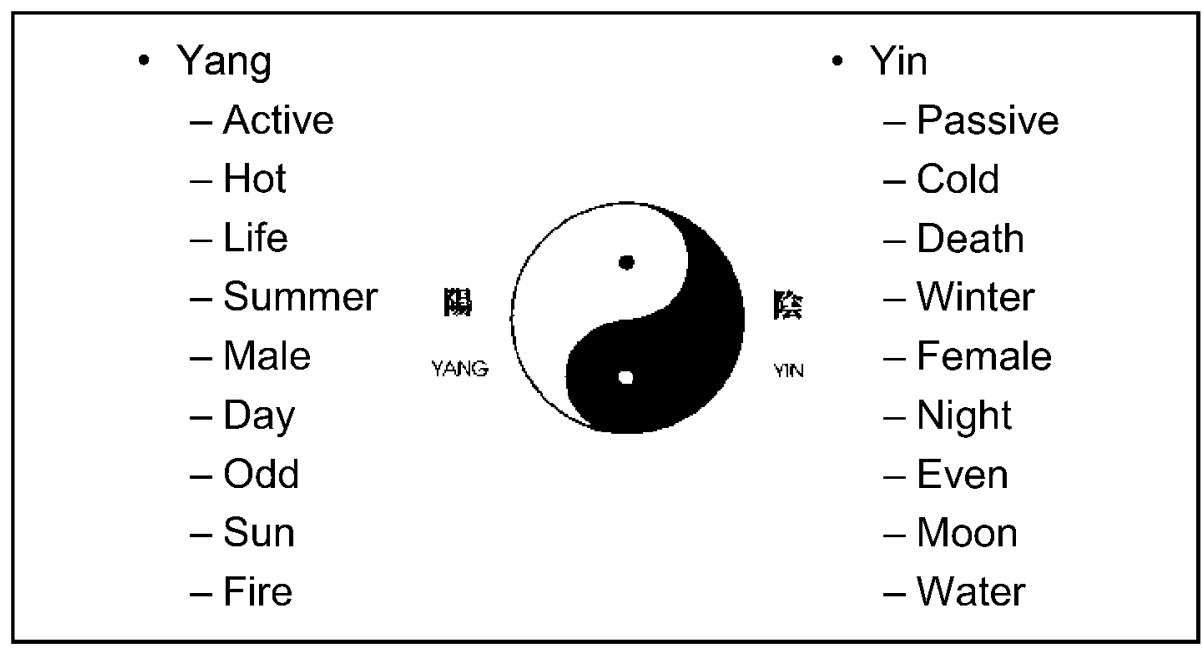

Figure 1. Knowledge Consists Simultaneously of Both "Hard" and "Soft" Knowledge (Adapted from "The Duality of Knowledge," P. Hildreth and C. Kimble, Information Research (8:1), 2002.)

edge can be exchanged through digital media. It recognizes that higher levels of tacit knowledge can be exchanged through face-to-face contact. However, knowledge can be made more transportable by increasing the hard/explicit element in relation to the soft/tacit element.

Assuming that knowledge is a critical input to production processes, then competitive advantage stems from the ability to integrate the specialized knowledge of individuals (Grant 1996; Nonaka 1994; Spender 2003). Therefore, one of the key issues underlying the knowledge-based view of the firm is to understand how knowledge is integrated into the firm to create competitive advantage (Hansen 1996). Informal networks such as NoPs are rapidly gaining attention within this view of the firm. Knowledge may be the organizations most valuable resource; however, no firm can possess all the knowledge it requires. Therefore, it must look outside its formal boundaries (Wasko and Faraj 2005). Nooteboom (2004) suggests that in dynamic fields, organizational innovations derive from knowledge exchange and learning from network connections that cross organizational boundaries. Organization members benefit through informal interaction by acquiring knowledge they did not have.

\section{CONCEPTUAL FRAMEWORK}

When individuals have a common practice, knowledge readily flows across that practice, enabling individuals to create social networks to support knowledge exchange (Brown and Duguid 2000). In fact, Brown and Duguid conclude that the key to competitive advantage is a firm's ability to coordinate autonomous CoPs internally and leverage the knowledge that flows into these communities from network connections. 


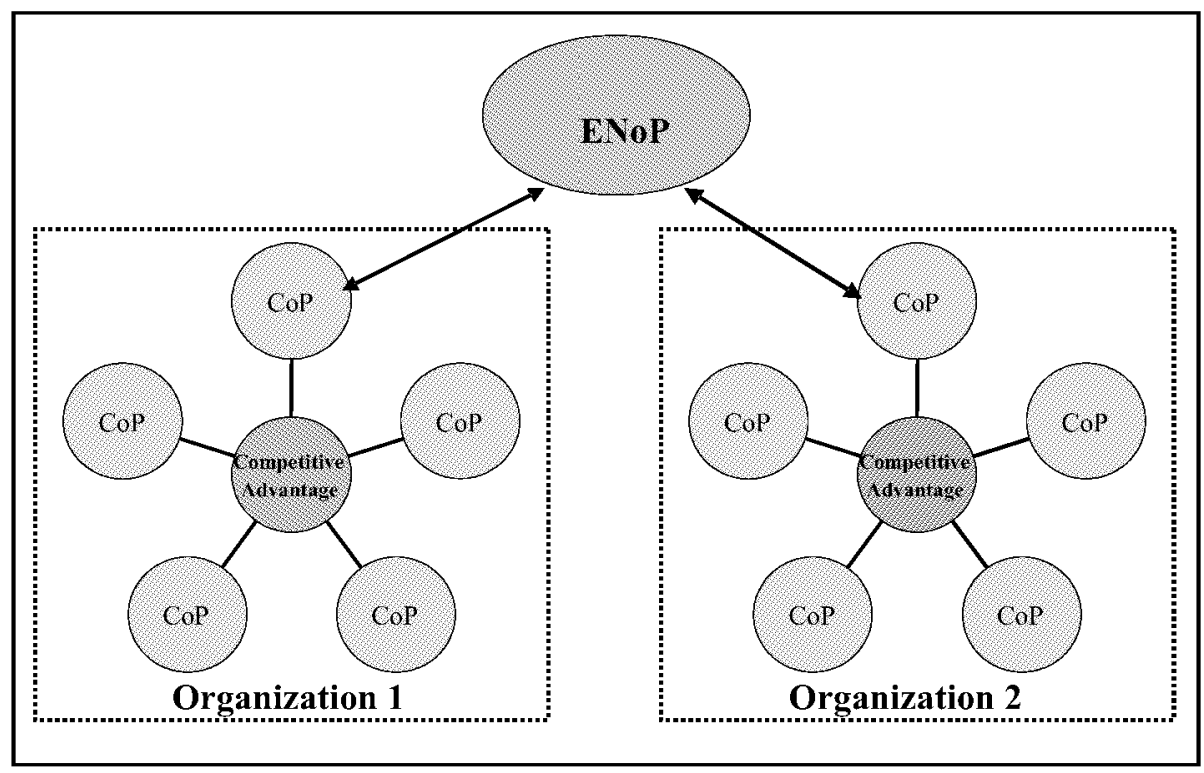

Figure 2. The Conceptual Framework

Findings from a recent study by Teigland and Wasko (2004) suggest that knowledge in a tightly knit CoP may be largely redundant, providing little additional information over what an individual may already know, thus impeding the ability to develop new and creative ideas. The highly efficient structures that support knowledge integration in a CoP may evolve into core rigidities and competency traps-inappropriate knowledge sets that preserve the status quo and limit new insights (Leonard and Sensiper 1998). One way to alleviate this concern is to use ENoPs to create "bridging links" between strong tie communities to enhance the flow of new ideas and knowledge. Electronic networks have certain advantages over social networks, mainly in rapidly transferring explicit knowledge, rapidly developing weak ties, and greatly reducing communication costs (Grandori and Soda 1995).

A conceptual framework that connects these views is presented in Figure 2. Internal to each organization are a number of CoPs. Through conversation, mentoring, war stories, etc., CoP members help each other to make sense of ambiguous, problemcentered situations. Due to the increased access of information and communication technologies, members of internal CoPs may also be members of external ENoPs. These individuals are able to acquire new knowledge from these external sources and integrate it into their internal CoPs. Through this process they are able to build competitive advantage by combining new and existing knowledge to generate novel ideas and solve complex problems.

A key question for researchers and practitioners is how to turn an empty electronic space into a vital, active forum devoted to knowledge exchange (Teigland and Wasko 2004). This research contributes to this inquiry by focusing specifically on the structural properties of ENoPs and their relationship with successful knowledge exchange. Structural property concepts are reviewed in the following section. 


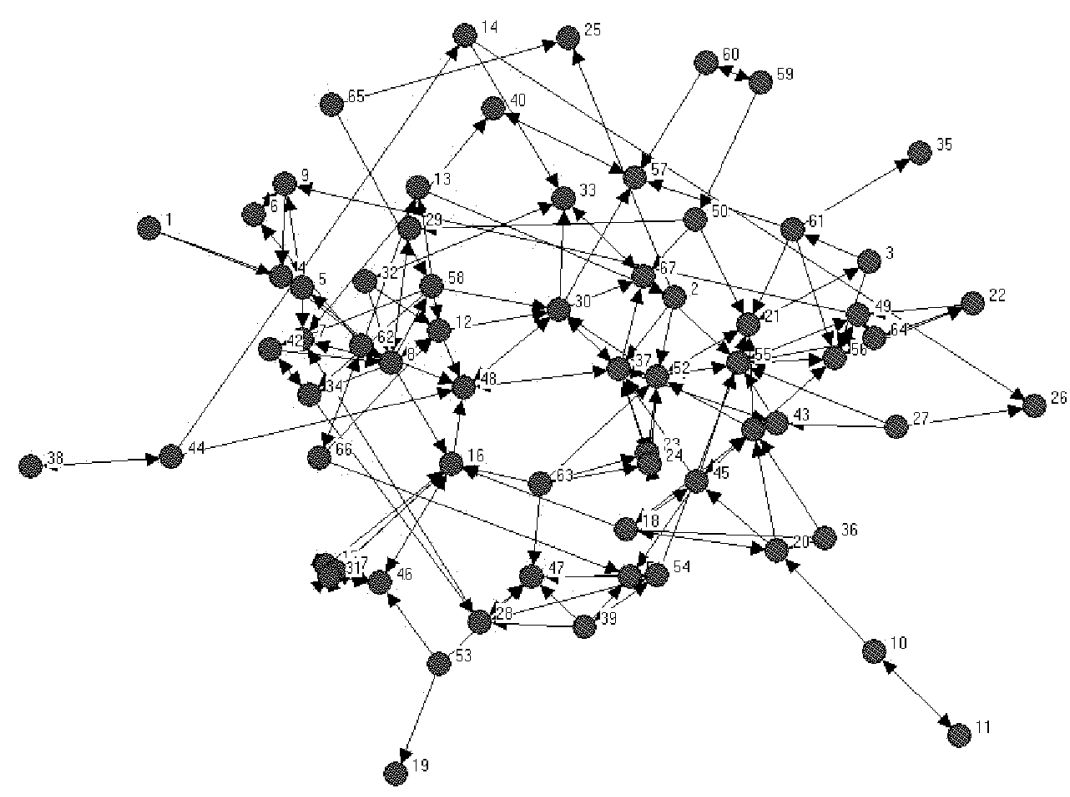

Figure 3. Social Network Map

\section{SOCIAL NETWORK THEORY}

In the field of social psychology, an important tradition of study on networks is that of social network theory. Social network theory views social relationships in terms of nodes and ties. Nodes are the individual actors within the networks, and ties are the relationships between the actors. Social network theory indicates the ways in which they are connected through various social familiarities ranging from casual acquaintance to close familial bonds. In its most simple form, a social network is a map of all of the relevant ties between the nodes being studied (see Figure 3).

The power of social network theory stems from its difference from traditional sociological studies, which assume that it is the attributes of individual actors that matter. Social network theory produces an alternate view, where the attributes of individuals are less important than their relationships and ties with other actors within the network. It suggests that at least some properties and outcomes of a social network are a function of its complete structure and are not reducible to either an individual actor or a single link (Degenne and Forse 1999).

The structural properties of the social network help determine the network's usefulness to its individuals. When talking about the structural properties, what is meant is the impact of group communication structure on collective performance outcomes. Structural properties refer to concepts such as density, connectedness, centrality, core/ 
periphery structure, coreness, etc. Due to the length requirements of this paper, one structural property is selected - core/periphery structure - and its relationship with network performance is examined.

A network has a core/periphery structure if it can be partitioned into two sets: a core whose members are densely tied to each other, and a periphery, whose members have more ties to core members than each other (Borgatti and Everett 1999). Research into core/periphery structure has a long tradition dating back to $1940 \mathrm{~s}$ and $1950 \mathrm{~s}$. This body of literature consistently shows that networks with a strong core/periphery structure are better for the diffusion of routine information, while networks with a weak core/ periphery structure are better for solving complex tasks (see Figures 4 and 5). For example, Bavelas (1948) showed that communication nets with centralized structures (e.g., wheel) improved the diffusion of information in simple tasks while decentralized structures (e.g., circle) delayed the diffusion of information. Groups with decentralized communication nets took less time to finish complex tasks than groups with a centralized structure (Shaw 1964). More recently, Cummings and Cross (2003) found that a strong core/periphery structure was negatively related to group performance for complex, nonroutine work.

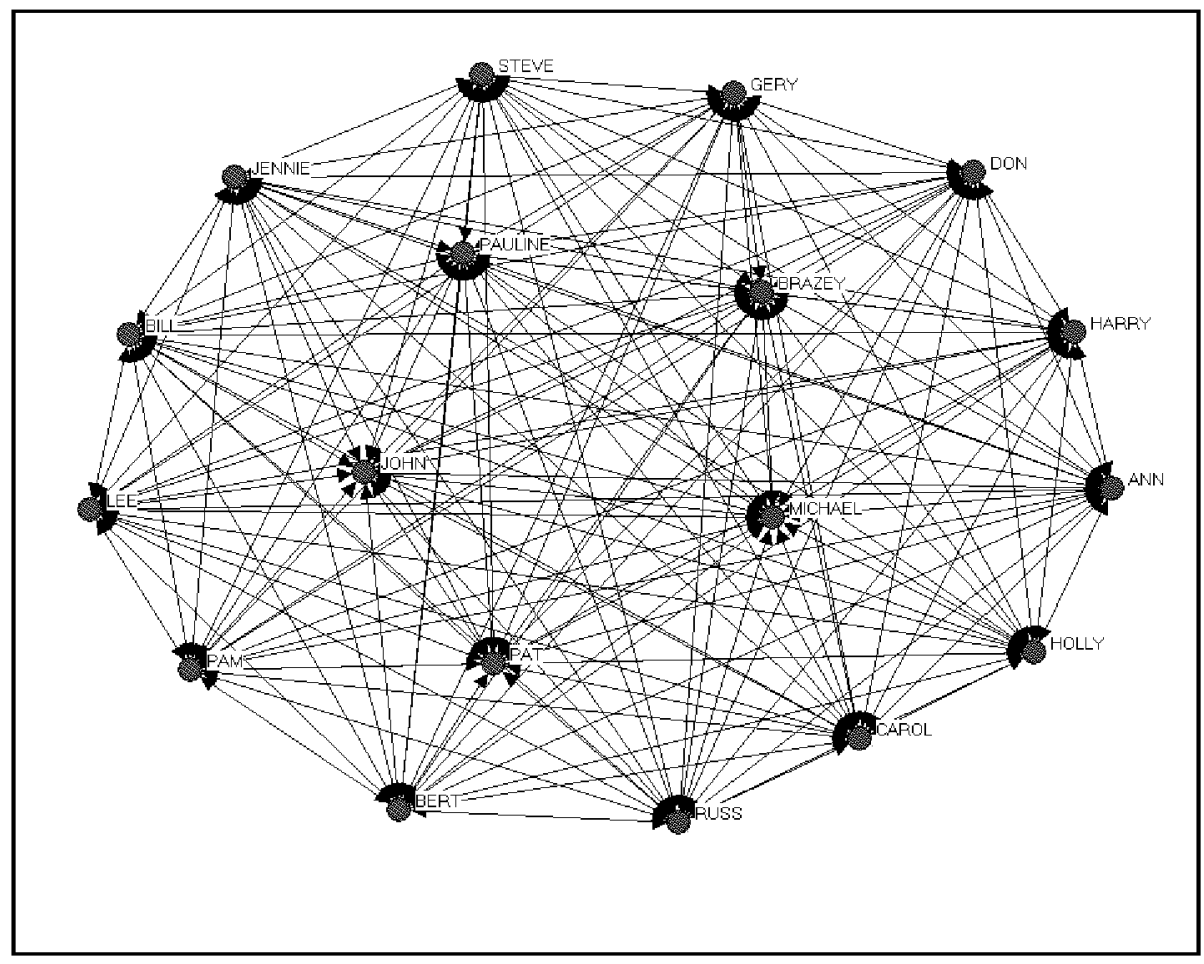

Figure 4. Weak Core/Periphery Structure 


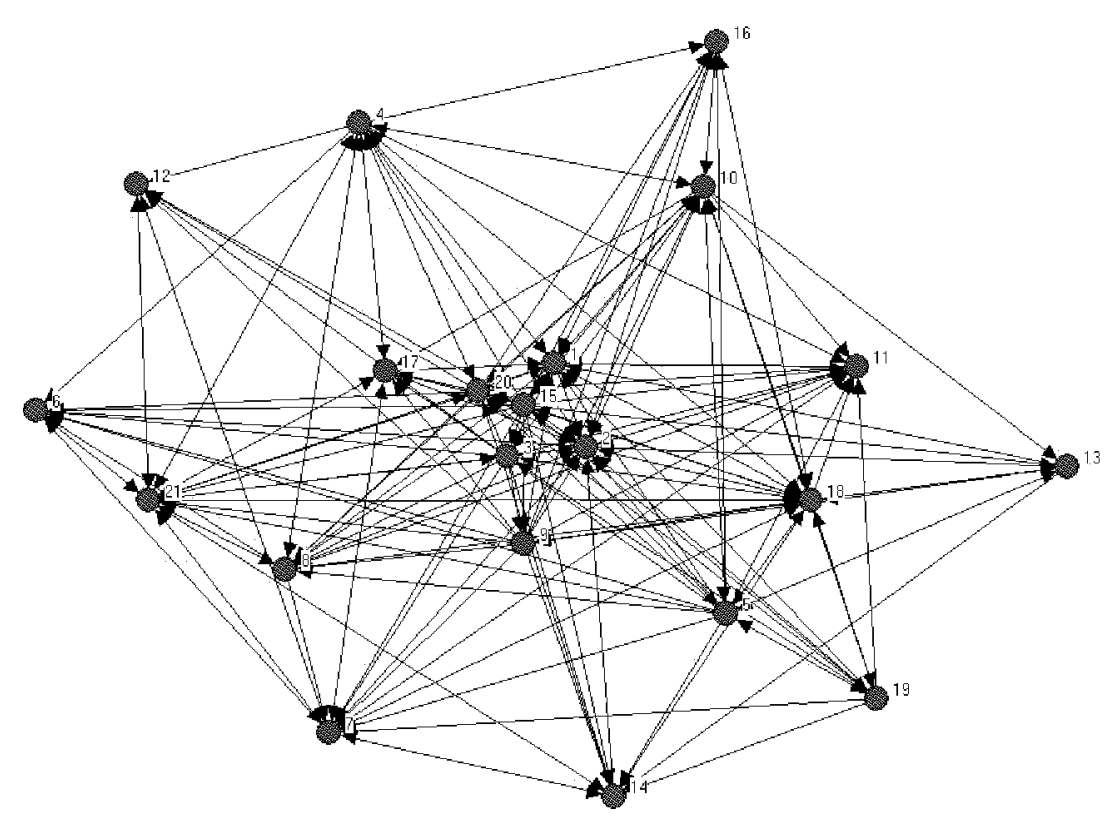

Figure 5. Strong Core/Periphery Structure

It has only been in recent years that network analysis has captured the attention of the business world on a broad scale. Yet despite the increase in the use of work groups in organizations, there has been relatively little social network research on the structural properties of natural work groups and the consequences for performance (Cummings and Cross 2003; Schenkel et al. 2001). Social network scholars have tended to focus on structural properties of ego-centric networks or bounded networks within an organization. Cummings and Cross also suggest that field work is needed to revisit which structures have meaningful consequences for performance.

\section{METHODOLOGY}

ENoP research is still in its infancy and we know little about the dynamics of knowledge exchange in these significant organizational forms. Previous research has been limited by the fact that researchers have tended to concentrate on only one ENoP, usually internal to one organization (Teigland and Wasko 2003, 2004; Wasko and Faraj 2005). Empirical evidence that links ENoP structures to performance is needed as previous research in the social network field shows that informal methods of knowledge transfer are more effective than formal processes (Burt 1992; Grant 1996). As a step in this direction, this research will address the following question: What is the relationship 
between ENoP structural properties and successful knowledge exchange for complex, non-routine work? A set of hypotheses relating the two variables (i.e., ENoP structural properties and successful knowledge exchange) will be developed and tested. Previous research will be extended by analyzing multiple categories of knowledge workers across multiple organizations.

The first stage of this research will be to identify six to eight interorganizational ENoPs. For example, one might be an open-source software network; another might be a discussion forum for chemical engineers. Once identified, the structural properties of the ENoPs will be measured using a tool called social network analysis. This tool provides both a graphical display of the network as well as precise mathematical measures of its structure (i.e., density, connectedness, centrality, core/periphery structure, coreness). The second stage will involve measuring the success of the knowledge exchanged through these electronic networks. Successful knowledge exchange in ENoPs is determined by both the quantity of knowledge exchanged as well as the quality. Knowledge quantity will be measured by a process called content analysis. To measure the quality of knowledge exchanged in an ENoP, an expert from each field will rate the usefulness of responses posted. A survey of ENoP participants will serve as a second measure of knowledge quality. For example, participants can be asked how useful they found the ENoP for solving complex problems. To test the hypotheses, the various measures of ENoP structural properties will be related to the measures for successful knowledge exchange.

\section{CONCLUSION}

This paper posits that there is a relationship between the structural properties of ENoPs and successful knowledge exchange. The knowledge-based view of the firm and social network theory are used to justify this claim. The knowledge-based view of the firm argues that knowledge is the firm's most important strategic asset while social network theory shows that network outcomes are determined by its structure. A conceptual framework linking a firm's competitive advantage to the interaction of faceto-face CoPs and interorganizational ENoPs has been presented. Further research will involve developing hypotheses that relate ENoP structures to successful knowledge exchange. These hypotheses will be applied to multiple categories of ENoPs and tested.

\section{References}

Bavelas, A. "A Mathematical Model for Group Structure," Human Organizations (7), 1948, pp. $17-30$.

Borgatti, S. P., and Everett, M. G. “Models of Core/Periphery Structures,” Social Networks (21), 1999, pp. $375-395$.

Bouty, I. "Interpersonal and Interaction Influences on Informal Resource Exchanges Between R\&D Researchers Across Organizational Boundaries," Academy of Management Journal (43:1), 2000, pp. 50-66.

Brown, J. S., and Duguid, P. The Social Life of Information, Boston: Harvard Business School Press, 2000. 
Buckingham Shum, S. "Negotiating the Construction and Reconstruction of Organizational Memories," Journal of Universal Computer Science (3:8), 1997, pp. 899-928.

Burt, R. Structural Holes: The Social Structure of Competition, Cambridge, MA: Harvard University Press, 1992.

Cross, R., Borgatti, S. P., and Parker, A. "Making Invisible Work Visible: Using Social Network Analysis to Support Strategic Collaboration," California Management Review (44:2), Winter 2002, pp. 25-46.

Cummings, J., and Cross, R. "Structural Properties of Work Groups and Their Consequences for Performance," Sacial Networks (25), 2003, pp. 197-210.

Davenport, T. H. Information Ecology, New York: Oxford University Press, 1997.

Degenne, A., and Forse, M. Introducing Social Networks, Thousand Oaks, CA: Sage Publications, 1999.

Drucker, P. Post-Capitalist Society, New York: Harper Business, 1994.

Glazer, R. "Measuring the Knower: Toward a Theory of Knowledge Equity," California Management Review (40:3), 1998, pp. 175-194.

Goldkuhl, G., and Barf, E. "Organizational Ability: Constituents and Congruencies," in Knowledge Management in the Sociotechnical World.: The Graffiti Continues, E. Coakes, D. Willis, and S. Clarke (eds.), London: Springer, 2002, pp. 30-42.

Grandori, A., and Soda, G. "Inter-Firm Networks: Antecedents, Mechanisms and Forms," Organization Studies (16:2), 1995, pp. 183-214.

Grant, R. M. "Knowledge and Organization," in Managing Industrial Knowledge: Creation, Transfer and Utilization, I. Nonaka and D. J. Teece (eds.), London: Sage Publications, 2001.

Grant, R. M. "Toward a Knowledge-Based Theory of the Firm," Strategic Management Journal (17), 1996, pp. 109-122.

Hansen, M. T. Knowledge Integration in Organizations, Boston: Harvard Business School Press, 1996.

Hildreth, P., and Kimble, C. "The Duality of Knowledge," Information Research (8:1), Paper Number 142, 2002 (available online at http:/InformationR.net/ir/8-1/paper142.html).

Huang, K. "Capitalizing Collective Knowledge for Winning Execution and Teamwork," Journal of Knowledge Management (1:2), 1997, pp. 149-209.

Jones, C., Hesterly, W. S., and Borgatti, S. P. "A General Theory of Network Governance: Exchange Conditions and Social Mechanisms," Academy of Management Review (22:4), 1997, pp. 911-945.

Leonard, D., and Sensiper, S. "The Role of Tacit Knowledge in Group Innovation," California Management Review (40:3), 1998, pp. 112-131.

Nonaka, I. "A Dynamic Theory of Organizational Knowledge Creation," Organization Science (5:1), 1994, pp. 14-37.

Nooteboom, B. Inter-Firm Collabortion, Learning and Networks, London: Routledge, 2004.

Schenkel, A., Teigland, R., and Borgatti, S. P. "Theorizing Structural Properties of Communities of Practice: A Social Network Approach," paper presented at the Academy of Management Conference, Organization and Management Division, Washington DC, 2001.

Shaw, M. E. (ed.). Communication Networks, New York: Academic Press, 1964.

Spender, J. C. "Knowledge Fields: Some Post-9/11 Thoughts About the Knowledge-Based Theory of the Firm," in Handbook on Knowledge Management, C. W. Holsapple (ed.), New York: Springer, 2003, pp. 59-72.

Teece, D. J. "Research Directions for Knowledge Management," California Management Review (40:3), 1998, pp. 289-292.

Teigland, R., and Wasko, M. "Integrating Knowledge Through Information Trading: Examining the Relationship Between Boundary Spanning Communication and Individual Performance," Decision Sciences (34:2), Spring 2003, pp. 261-287. 
Teigland, R., and Wasko, M. "Extending Richness with Reach: Participation and Knowledge Exchange in Electronic Networks of Practice," in Knowledge Networks: Innovation Through Communities of Practice, P. Hildreth and C. Kimble (eds.), London: Idea Group, 2004.

Van Maanen, J., and Barley, S. R. "Occupational Communities: Culture and Control in Organizations," in Research in Organizational Behavior, B. M. Staw and L. L. Cummings (eds.), Greenwich, CT: JAI Press, 1984.

Wasko, M. M., and Faraj, S. "Why Should I Share? Examining Social Capital and Knowledge Contribution in Electronic Networks of Practice," MIS Quarterly (29:1), March 2005, pp. $35-57$.

\section{About the Author}

Eoin Whelan is a lecturer in information systems at the National University of Ireland, Galway, where he teaches information systems strategy, e-commerce, and computer programming. He is also undertaking a Ph.D. with the Centre for Innovation \& Structural Change at the same institution. Prior to commencing his Ph.D., Eoin worked as a management accountant in Ireland, New Zealand, and the United States. He earned his Master's degree by research from the University of Limerick in 2002 and was awarded the Government of Ireland Scholarship in Humanities and Social Sciences for this research. Eoin can be reached at eoin.whelan@ nuigalway.ie. 